\title{
Prevalence and incidence of liver enzyme elevations in a pooled oncology clinical trial cohort
}

\author{
Sumitra Shantakumar ${ }^{a,}{ }^{*}$, Sarah Landis $^{\mathrm{b}}$, Andy Lawton ${ }^{\mathrm{b}}$, Christine M. Hunt $^{\mathrm{c}}$ \\ ${ }^{a}$ Worldwide Epidemiology, GlaxoSmithKline, Gateway West, Singapore \\ ${ }^{\mathrm{b}}$ Worldwide Epidemiology, GlaxoSmithKline, Stockley Park, United Kingdom \\ ${ }^{\mathrm{c}}$ Department of Veterans Affairs, Durham VA Medical Center, North Carolina, USA
}

\section{A R T I C L E I N F O}

Article history:

Received 20 January 2016

Received in revised form 23 March 2016

Accepted 24 March 2016

Available online 26 March 2016

\section{Keywords:}

Hepatotoxicity

Liver injury

Clinical trial

Oncology

Metastasis

Liver enzyme

Bilirubin

Alanine aminotransferase

Truncated robust multivariate outlier

detection

\begin{abstract}
A B S T R A C $T$
Few epidemiologic studies describe longitudinal liver chemistry (LC) elevations in cancer patients. A population-based retrospective cohort was identified from 31 Phase 2-3 oncology trials (excluding targeted therapies) conducted from 1985 to 2005 to evaluate background rates of LC elevations in patients $(\mathrm{n}=3998)$ with or without liver metastases. Patients with baseline liver metastases (29\% of patients) presented with a $3 \%$ prevalence of alanine transaminase (ALT) $\geq 3 x$ upper limits normal (ULN) and $0.2 \%$ prevalence of bilirubin $\geq 3 x U L N$. During follow-up, the incidence (per 1000 person-months) of new onset ALT elevations $\geq 3$ XULN was 6.1 (95\% CI: 4.5, 8.0) and $2.2(95 \% \mathrm{CI}: 0.9,4.5)$ in patients without and with liver metastases, respectively. No new incident cases of ALT and bilirubin elevations suggestive of severe liver injury occurred among those with liver metastases; a single case occurred among those without metastasis. Regardless of the presence of liver metastases, LC elevations were rare in cancer patients during oncology trials, which may be due to enrollment criteria. Our study validates uniform thresholds for detection of LC elevations in oncology studies and serves as an empirical referent point for comparing liver enzyme abnormalities in oncology trials of novel targeted therapies. These data support uniform LC stopping criteria in oncology trials.
\end{abstract}

(C) 2016 Elsevier Inc. All rights reserved.

\section{Introduction}

For the last 50 years, liver safety issues have been the most frequent cause of safety-related drug marketing withdrawals (US FDA, 2009) warranting close monitoring of liver safety in drug development clinical trials. During oncology clinical trials, serious hepatic events may require immediate drug cessation and affect long-term outcomes. In addition to monitoring clinical symptoms, laboratory tests monitoring the presence of liver enzyme abnormalities allow for the timely detection of potential hepatotoxicity. Through liver chemistry monitoring, drug-induced functional impairment of the liver and irreversible injury may be avoided or

\footnotetext{
Abbreviations: ALT, alanine transaminase; ALP, alkaline phosphatase; AST, aspartate transaminase; BILI, bilirubin; xULN, upper limits normal.

* Corresponding author. Worldwide Epidemiology, R\&D Glaxosmithkline 150 Beach Road, \#26-00, Gateway West Singapore 189720 Singapore.

E-mail addresses: sumitra.y.shantakumar@gsk.com (S. Shantakumar), sarah.h. landis@gsk.com (S. Landis), andy.m.lawton@gsk.com (A. Lawton), christine.hunt@ va.gov (C.M. Hunt).
}

minimized.

Most drugs associated with liver injury cause hepatocellular damage (Weil et al., 2008; Lee, 2003), which is detectable through elevated levels of aminotransferase enzymes leaked from injured liver cells (US FDA, 2009). Serum elevations of alanine aminotransferase (ALT) and bilirubin (BILI) are particularly sensitive for detecting suspected drug-induced liver injury (US FDA, 2009). ALT is also more specific for liver injury than aspartate transaminase (AST) (Green and Flamm, 2002). The elevation of ALT is generally crudely proportional to the degree of injury; elevations exceeding 3 times the upper limits normal (xULN) suggest modest liver injury (Kaplowitz, 2005). Though some drugs may increase liver enzyme levels, severe hepatocellular injury is accompanied by an impaired ability of the liver to clear plasma bilirubin. In severe drug-induced liver injury, simultaneous elevations in ALT and bilirubin indicate the potential for acute liver failure (Kaplowitz, 2005).

Small case series have reported marked liver chemistry elevations and fulminant hepatic failure in patients with liver metastases or infiltrating neoplasms (Rajvanshi et al., 2005; Rowbotham et al., 1998). This study's focus is to understand the distribution of liver 
injury events associated with liver metastases or potential druginduced mechanisms in oncology clinical trials. In oncology clinical trials, liver chemistry elevations also arise from viral hepatitis (Rajvanshi et al., 2005), hypotension/ischemia, sepsis, acute vascular events, and non-hepatic causes (Green and Flamm, 2002), but these factors are beyond the scope of this report.

In this study we pooled data from 31 oncology clinical trials to assess the rates of liver chemistry elevations among 3998 enrolled patients with and without baseline liver metastases. Pooling data is advantageous for assessing the risk of rare outcomes, such as laboratory indicators of mild, moderate and severe drug-induced liver injury, and for assessing whether risk varies across patient characteristics. Accounting for the presence of liver metastases at patient enrollment, our study seeks to establish the background prevalence and incidence rates of liver injury events in a large, representative population of patients with solid tumors. Select demographic, clinical, and nutritional risk factors were examined among those with elevated levels of ALT.

\section{Materials and methods}

This study includes 31 Phase $2(\mathrm{n}=26)$ and Phase $3(\mathrm{n}=5)$ oncology trials conducted by GlaxoSmithKline or its heritage companies between 1985 and 2005 (Supplementary Material); all trials included liver chemistry testing. Clinical trials of targeted cancer therapies were excluded from the pooled dataset since a primary objective was to establish background rates of potential liver injury in a representative sample of the general oncology population. All patients with at least one follow-up liver chemistry elevation had their maximal measured value described. The outcome of interest was a liver chemistry elevation greater than or equal to pre-defined upper limit of normal (ULN) threshold. Baseline was defined as the period between the initial study visit up to the day before the first administration of investigational product. If more than one set of laboratory values were available during the baseline period, the tests performed closest to the initiation of investigational product were used.

Baseline prevalence and incidence estimates for liver chemistry thresholds of alanine transaminase (ALT), aspartate transaminase (AST), bilirubin (BILI) and alkaline phosphatise (ALP) were examined. The baseline prevalence of selected liver chemistry tests above the ULN threshold was defined as the proportion (\%) of patients with an elevation greater than or equal to pre-defined ULN threshold levels among all patients with laboratory values during the baseline period. The incidence proportion (\%) and incidence rates per 1000 person-months of new onset elevations while on treatment were calculated. For incidence analyses, patients were considered at-risk if they had normal baseline liver chemistries and at least one follow-up test. Person-time at-risk was censored at either the date of reaching a particular elevation threshold or the date of the final administration of investigational product among patients who did not experience the outcome. Analyses of prevalence and incidence were conducted separately for each liver chemistry and each threshold definition; an individual could contribute to the numerator in more than one analysis of different liver chemistry tests and thresholds. A combination endpoint suggesting possible severe liver injury (ALT or AST $\geq 3 \times$ ULN and BILI $\geq 2 x U L N$ and ALP $<2 x U L N$ ) was also evaluated (US FDA, 2009). Lastly, for patients with at least one follow-up elevation, the distribution of maximal measured liver chemistry elevations was described. All prevalence and incidence analyses were stratified by the presence of baseline liver metastases. Assessment of metastatic progression varied across the 31 trials. Our pooled study did not require confirmation of baseline liver metastases by medical imaging.
Lastly, demographic, clinical, and nutritional factors potentially associated with ALT elevations were examined. The baseline prevalence and incidence proportion of ALT $\geq 3 \times$ ULN were stratified by these covariates and risk ratios (RR) comparing each level of the covariate to a referent group were calculated. The cancer type with the lowest incidence at follow-up was chosen as the referent group (breast cancer) for tumour type analyses. Corresponding confidence intervals using an approximate method were calculated (Armitage et al., 2002). All analyses were conducted using SAS version 9.1.

\section{Results}

Liver chemistries were examined in 3998 patients in 31 Phase 2 and 3 oncology trials. The aggregated dataset included clinical trials of lung cancer $(n=10$ trials), colorectal cancer $(n=6)$, breast cancer $(\mathrm{n}=5)$, ovarian cancer $(\mathrm{n}=5)$, prostate cancer $(\mathrm{n}=1)$, nonHodgkin lymphoma ( $\mathrm{n}=1)$, Kaposi sarcoma $(\mathrm{n}=1)$, and leukemia $(n=2)$. In these trials, baseline laboratory values for ALT, AST, ALP, and bilirubin were obtained in $81 \%(n=3223), 61 \%(n=2451)$, $86 \%(n=3424)$ and $92 \%(n=3665)$ of patients respectively. The median patient age was 61 years (range: $18-90$ years). The median length of follow-up was 119 days (range: $1-1111$ days). At baseline, the majority of patients had locally advanced or metastatic disease and $29 \%$ had liver metastases. In most trials, liver chemistry inclusion criteria were specified, and typically required levels of transaminases and bilirubin $\leq 2 x$ ULN in the absence of liver metastases and $\leq 5 \mathrm{x}$ ULN in the presence of liver metastases.

Across all liver chemistries and threshold levels, there was a higher baseline prevalence of enzyme elevations among patients with liver metastases, compared to patients without liver metastases. Elevations $<10 \mathrm{x}$ ULN were generally twice as common among those with baseline liver metastases compared to those without metastases (Table 1). At baseline, transaminases (ALT, AST) at $\geq 3$ xULN affected $5 \%$ or less of patients with liver metastases and less than $2 \%$ of patients without liver metastases (Table 1 ). Baseline ALP $\geq 3 \mathrm{x}$ ULN was more common, identified in $17.1 \%$ of those with liver metastases and $3.7 \%$ of patients without liver metastases. Baseline bilirubin $\geq 2 \mathrm{x}$ ULN affected fewer than $1 \%$ of those with or without liver metastases (with most patients exceeding this threshold excluded from trials). Potentially severe liver injury is identified by concomitant transaminase and bilirubin elevations. At baseline, a single patient without liver metastases exhibited concomitant transaminase and bilirubin elevations (ALT or AST $\geq 3$ XULN and BILI $\geq 2 x U L N$ and ALP $<2 x U L N)$, yielding a prevalence of $0.04 \%$ (95\%CI: $0 \%-0.2 \%$ ); no such combination occurrence was observed among those with baseline liver metastases.

Overall during follow-up, an incident elevation of ALT $\geq 3 x$ XLN affected $2.8 \%$ of patients without metastases, and only $1.2 \%$ of patients with liver metastases (Table 2). The incidence of AST $\geq 3 x U L N$, a nonspecific injury marker, was twice as common among subjects without liver metastases (10.6\%) compared to subjects with baseline liver metastases (5.1\%). An incident elevation of ALP $\geq 3 \times$ XULN affected $1 \%$ or less of all patients. Bilirubin $\geq 3 x U L N$, the threshold for clinical jaundice, affected $0.6 \%$ of those without liver metastases and $2.0 \%$ of those with baseline liver metastases. Regardless of liver metastases, the incidence of moderate liver chemistry elevations (i.e. $\geq 5 \mathrm{xULN}$ ) was less than $1 \%$. Bilirubin was the only analyte with higher incidence rates among patients with liver metastases. The incidence of ALT or AST elevations of 1-5xULN was higher for patients without liver metastases, compared to those with metastases. Only one patient without liver metastases exhibited concomitant transaminase and bilirubin elevations (ALT or AST $\geq 3$ XULN and BILI $\geq 2 x U L N$ and ALP $<2 x U L N$ ) 
Table 1

Prevalence of elevated liver chemistry values among cancer clinical trial patients at baseline.

\begin{tabular}{|c|c|c|c|c|c|c|c|}
\hline \multirow[t]{2}{*}{ Hepatic lab test } & \multirow[t]{2}{*}{ Threshold value } & \multicolumn{3}{|c|}{ Cancer Patients without liver metastases } & \multicolumn{3}{|c|}{ Cancer Patients with liver metastases } \\
\hline & & $\mathrm{N}$ evaluated ${ }^{\mathrm{a}}$ & $\mathrm{N}(\%)$ & $95 \% \mathrm{Cl}^{\mathrm{b}}$ & $\mathrm{N}$ evaluated ${ }^{\mathrm{a}}$ & $\mathrm{N}(\%)$ & $95 \% \mathrm{Cl}^{\mathrm{b}}$ \\
\hline \multirow[t]{4}{*}{ ALT } & $\geq 1 \mathrm{xULN}$ & 2257 & $357(15.8)$ & $14.3,17.4$ & 966 & $303(31.4)$ & $28.5,34.4$ \\
\hline & $\geq 3 \times U L N$ & & $37(1.6)$ & $1.2,2.3$ & & $30(3.1)$ & $2.1,4.4$ \\
\hline & $\geq 5 x U L N$ & & $7(0.3)$ & $0.1,0.6$ & & $7(0.7)$ & $0.3,1.5$ \\
\hline & $\geq 10 \times U L N$ & & $2(0.1)$ & $0.0,0.3$ & & $0(0)$ & - \\
\hline \multirow[t]{4}{*}{$\mathrm{AST}^{\mathrm{C}}$} & $\geq 1 \mathrm{xULN}$ & 2230 & $299(13.4)$ & $12.0,14.9$ & 221 & $71(32.1)$ & $26.0,38.7$ \\
\hline & $\geq 3 \times U L N$ & & $20(0.9)$ & $0.5,1.4$ & & $12(5.4)$ & $2.8,9.3$ \\
\hline & $\geq 5 \mathrm{xULN}$ & & $5(0.2)$ & $0.1,0.5$ & & $2(0.9)$ & $0.1,3.2$ \\
\hline & $\geq 10 x U L N$ & & $0(0)$ & - & & $1(0.5)$ & $0.0,0.3$ \\
\hline \multirow[t]{4}{*}{ ALP } & $\geq 1 \times$ ULN & 2368 & $887(37.2)$ & $35.2,39.2$ & 1056 & $707(67.0)$ & $64.0,69.8$ \\
\hline & $\geq 2 \mathrm{xULN}$ & & $201(8.4)$ & $7.3,9.6$ & & 316 (29.9) & $27.2,32.8$ \\
\hline & $\geq 3 x U L N$ & & 87 (3.7) & $2.9,4.5$ & & $180(17.1)$ & $14.8,19.5$ \\
\hline & $\geq 5 \mathrm{xULN}$ & & $40(1.7)$ & $1.2,2.3$ & & $96(9.1)$ & $7.4,11.0$ \\
\hline \multirow[t]{5}{*}{ Bilirubin } & $\geq 1 \mathrm{xULN}$ & 2589 & $61(2.4)$ & $1.8,3.0$ & 1076 & $49(4.6)$ & $3.4,6.0$ \\
\hline & $\geq 2 x U L N$ & & $8(0.3)$ & $0.1,0.6$ & & $6(0.6)$ & $0.2,1.2$ \\
\hline & $\geq 3 \times$ ULN & & $4(0.2)$ & $0.0,0.4$ & & $2(0.2)$ & $0.0,0.7$ \\
\hline & $\geq 5 x U L N$ & & $1(0.04)$ & $0.0,0.2$ & & $0(0)$ & - \\
\hline & $\geq 10 x U L N$ & & $0(0)$ & - & & $0(0)$ & - \\
\hline Combination $^{\mathrm{d}}$ & & 2359 & $1(0.04)$ & $0.0,0.2$ & & $0(0)$ & - \\
\hline
\end{tabular}

a Subjects with a baseline laboratory value for that particular liver chemistry test.

b $95 \%$ confidence intervals (CI) estimated using the Clopper-Pearson approach.

c The denominator for patients with liver metastases is low because trial FUMA3008 $(\mathrm{N}=964)$ did not have AST data, but this trial makes up $772(80 \%)$ of the total patients with liver metastases.

d ALT or AST $\geq 3 x U L N$ and BILI $\geq 2 x U L N$ and ALP $<2 x U L N$.

Table 2

Cumulative incidence counts and incidence rates per 1000 person months ( $\mathrm{pm}$ ) of liver chemistry elevations in cancer patients during follow up.

\begin{tabular}{|c|c|c|c|c|c|c|c|c|c|c|c|}
\hline \multirow{2}{*}{\multicolumn{2}{|c|}{$\begin{array}{c}\text { Hepatic lab test Threshold } \\
\text { value }\end{array}$}} & \multicolumn{5}{|c|}{ Cancer Patients without liver metastases } & \multicolumn{5}{|c|}{ Cancer Patients with liver metastases } \\
\hline & & \multicolumn{2}{|c|}{ N evaluated ${ }^{\mathrm{a}} \mathrm{N}(\%)$} & \multirow{2}{*}{$\begin{array}{c}\begin{array}{l}\text { Person } \\
\text { months }\end{array} \\
6374\end{array}$} & \multicolumn{2}{|c|}{ IR per 1000pm 95\% CI } & \multicolumn{2}{|c|}{ N evaluated ${ }^{\mathrm{a}} \mathrm{N}(\%)$} & \multirow{2}{*}{$\begin{array}{l}\begin{array}{l}\text { Person } \\
\text { months }\end{array} \\
2535\end{array}$} & \multicolumn{2}{|c|}{ IR per $1000 \mathrm{pm} 95 \% \mathrm{CI}$} \\
\hline \multirow[t]{4}{*}{ ALT } & $\geq 1 \mathrm{xULN}$ & 1732 & $505(29.2)$ & & 79.2 & $72.5,86.5$ & 565 & $163(28.9)$ & & 64.3 & $54.8,75.0$ \\
\hline & $\geq 3 \mathrm{xULN}$ & & $49(2.8)$ & 8053 & 6.1 & $4.5,8.0$ & & $7(1.2)$ & 3205 & 2.2 & $0.9,4.5$ \\
\hline & $\geq 5 \mathrm{xULN}$ & & $15(0.9)$ & 8153 & 1.8 & $1.0,3.0$ & & $1(0.2)$ & 3218 & 0.3 & $0.0,1.7$ \\
\hline & $\geq 10 x U L N$ & & $1(0.1)$ & 8189 & 0.1 & $0.0,0.7$ & & $1(0.2)$ & 3218 & 0.3 & $0.0,1.7$ \\
\hline \multirow[t]{4}{*}{ AST } & $\geq 1 \mathrm{xULN}$ & 1842 & $529(28.7)$ & 7092 & 74.6 & $68.4,81.2$ & 138 & 37 (26.8) & 466 & 79.5 & $55.4,109.5$ \\
\hline & $\geq 3 \times$ ULN & & $196(10.6)$ & 8886 & 4.6 & $3.3,6.3$ & & $7(5.1)$ & 555 & 5.4 & $1.1,15.8$ \\
\hline & $\geq 5 \times$ ULN & & $14(0.8)$ & 8972 & 1.6 & $0.9,2.6$ & & $1(0.7)$ & 555 & 1.8 & $0.1,10.0$ \\
\hline & $\geq 10 X U L N$ & & $2(0.1)$ & 9006 & 0.2 & $0.0,0.8$ & & $0(0)$ & 555 & 0 & - \\
\hline \multirow[t]{4}{*}{ ALP } & $\geq 1 \mathrm{xULN}$ & 1438 & $570(39.6)$ & 5618 & 101.5 & $93.2,110.0$ & 324 & 135 (41.7) & 1344 & 100.5 & $84.2,118.9$ \\
\hline & $\geq 2 \mathrm{xULN}$ & & $42(2.9)$ & 7734 & 5.4 & $3.9,7.3$ & & $7(2.2)$ & 1933 & 3.6 & $1.5,7.5$ \\
\hline & $\geq 3 \times U L N$ & & $14(1.0)$ & 7806 & 1.8 & $1.0,3.0$ & & $3(0.9)$ & 1937 & 1.5 & $0.3,4.5$ \\
\hline & $\geq 5 \mathrm{xULN}$ & & $3(0.2)$ & 7826 & 0.4 & $0.1,1.1$ & & $0(0)$ & 1942 & 0 & - \\
\hline \multirow[t]{5}{*}{ Bilirubin } & $\geq 1 \mathrm{xULN}$ & 2375 & $284(12.0)$ & 10,453 & 27.2 & $24.1,30.5$ & 923 & $195(21.1)$ & 4062 & 48.0 & $41.5,55.2$ \\
\hline & $\geq 2 x U L N$ & & 37 (1.6) & 11,519 & 3.2 & $2.3,4.4$ & & $33(3.6)$ & 4755 & 6.9 & $4.7,9.7$ \\
\hline & $\geq 3 \times$ ULN & & $15(0.6)$ & 11,604 & 1.3 & $0.7,2.1$ & & $18(2.0)$ & 4790 & 3.8 & $2.2,5.9$ \\
\hline & $\geq 5 \mathrm{xULN}$ & & $8(0.3)$ & 11,627 & 0.7 & $0.3,1.3$ & & $8(0.9)$ & 4797 & 1.7 & $0.7,3.3$ \\
\hline & $\geq 10 x U L N$ & & $3(0.1)$ & 11,638 & 0.3 & $0.1,0.8$ & & $2(0.2)$ & 4798 & 0.4 & $0.1,1.5$ \\
\hline \multicolumn{2}{|c|}{ Combination $^{\mathrm{b}}$} & 1321 & $1(0.1)$ & 7192 & 0.1 & $0.0-0.8$ & 255 & $0(0)$ & 1549 & 0 & - \\
\hline
\end{tabular}

a Subject who were normal at baseline and had at least one follow-up result for that particular liver chemistry.

b ALT or AST $\geq 3 x U L N$, BILI $\geq 2 x U L N$, and ALP $<2 x U L N$; ALT or AST, ALP and Bilirubin were normal at baseline.

yielding an incidence rate of 1 per 10,000 person-months. No such occurrence was observed among those with baseline liver metastases.

In patients with normal liver chemistries at baseline who later exhibited at least one liver chemistry elevation during follow-up, the maximum elevation was assessed (Fig. 1). Among these elevations, the majority were $<2 x U L N(75 \%-92 \%)$ and less than $5 \%$ were $>5 x U L N$. Maximum elevations $\geq 5 x U L N$ were most likely to occur for bilirubin among those with liver metastases at baseline.

Demographic, clinical, and nutritional factors associated with an incident ALT $\geq 3$ ULN were examined (Table 3). Factors associated with ALT $\geq 3$ ULN included: a diagnosis of chronic liver disease (Relative Risk $[\mathrm{RR}]=3.58 ; 95 \% \mathrm{CI}=1.35,9.49$ ), HIV infection $(\mathrm{RR}=6.19 ; 95 \% \mathrm{CI}=3.43,11.15)$, and anemia $(\mathrm{RR}=3.52 ; 95 \%$ $\mathrm{CI}=1.48,8.34)$. Compared to breast cancer patients, those with myelodysplastic syndrome were more likely to have an incident ALT $\geq 3 x U L N(R R=11.71,95 \% \mathrm{CI}=1.56,87.78)$. In contrast, the presence of liver metastases was associated with a lower relative risk of ALT $\geq 3 \mathrm{ULN}(\mathrm{RR}=0.44,95 \% \mathrm{CI}=0.2,0.96)$. Body mass index, diabetes, and albumin were not associated with ALT $\geq 3$ ULN.

\section{Discussion}

This study examined the prevalence and incidence of liver chemistry elevations across Phase 2-3 oncology trials totaling nearly 4000 oncology patients, a quarter of whom presented with liver metastases at baseline; trials involving targeted therapies were excluded and overall these trials excluded patients with baseline liver chemistry elevations $>5 x$ XLN at enrollment. The 31 trials in the pooled analysis were representative of general 


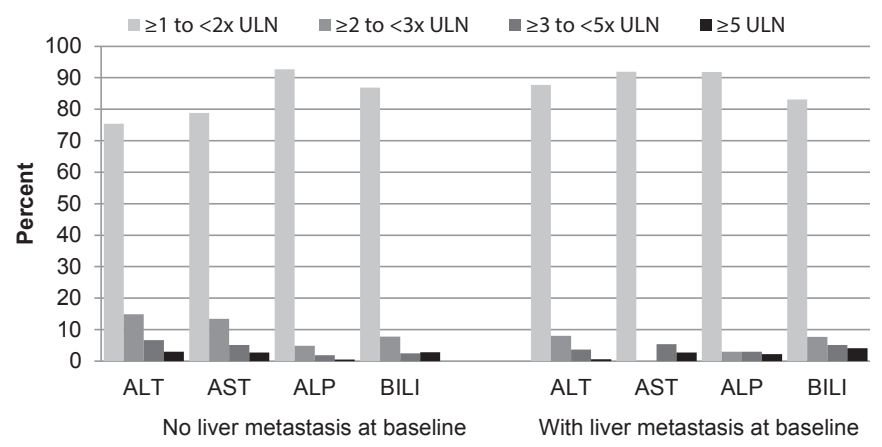

Fig. 1. Maximum alanine aminotransferase (ALT), aspartate transaminase (AST), alkaline phosphatase (ALP), and bilirubin (BILI) elevations in relation to the upper limits normal (ULN) measured during follow-up in cancer patients with or without liver metastasis.

oncology trials and included the most common solid tumors. Our primary goal was to establish background rates of liver enzyme elevations and validate liver enzyme safety thresholds for use in current and future studies of targeted therapies and clinical trials involving oncology patients. We investigated differences in the prevalence and incidence of liver chemistry elevations among patients who presented with and without liver metastases at baseline enrollment. Modest liver chemistry elevations were observed in this pooled oncology clinical trial database.

At baseline, modest liver chemistry elevations were twice as common in cancer patients with liver metastases, compared to those without metastases. However, even among patients presenting with baseline metastases, there was a low prevalence of elevated liver tests: only a $3 \%$ prevalence of ALT $\geq 3 x U L N$ and $0.2 \%$ prevalence of bilirubin $\geq 3 x U L N$ were observed. Excluding alkaline phosphatase, which increases with metastases (Green and Flamm, 2002), prevalent and incident liver chemistries $\geq 10 x U L N$ affected less than 1 in 500 patients.

The incidence of liver chemistry elevations was similar during follow-up regardless of the status of metastases at baseline. Both the prevalence and incidence of liver chemistry elevations $>3 x U L N$ were low in all patients, though the primary study exclusion criteria are likely responsible for the low prevalence. Among risk factors for elevated ALT, chronic liver disease, HIV, anemia and myelodysplastic syndrome were associated with a 3.5- to over 11fold increased relative risk of ALT $\geq 3 x U L N$. Liver metastases were associated with a lower relative risk of liver chemistry elevations, perhaps due to increased monitoring or vigilance among these

Table 3

Demographic, clinical, and nutritional factors associated with ALT $\geq 3$ ULN during follow-up.

\begin{tabular}{|c|c|c|c|c|}
\hline & \multicolumn{4}{|c|}{ All cancer Patients $(\mathrm{N}=2297)^{\mathrm{a}}$} \\
\hline & $\mathrm{N}$ & $\mathrm{n}(\%)$ with ALT $\geq 3 \mathrm{x}$ ULN & $\mathrm{RR}$ & $95 \% \mathrm{CI}$ \\
\hline Age, $65+$ years & 953 & $22(2.3)$ & 0.91 & $0.54,1.55$ \\
\hline Gender, Male & 1173 & $26(2.2)$ & 0.83 & $0.49,1.40$ \\
\hline \multicolumn{5}{|l|}{ BMI, $\mathrm{kg} / \mathrm{m}^{2}$} \\
\hline Underweight (<18.5) & 71 & $0(0)$ & - & - \\
\hline Normal (18.5-24.9) & 942 & $26(2.8)$ & Ref & \\
\hline Overweight (25.0-29.9) & 852 & $18(2.1)$ & 0.77 & $0.42,1.39$ \\
\hline Obese $(\geq 30.0)$ & 427 & $12(2.8)$ & 1.02 & $0.52,2.00$ \\
\hline Liver metastases at baseline & 565 & $7(1.2)$ & 0.44 & $0.20,0.96$ \\
\hline Alcohol Abuse & 23 & $0(0)$ & - & - \\
\hline Diabetes & 105 & $4(3.8)$ & 1.61 & $0.59,4.36$ \\
\hline Hepatitis B or C infection & 17 & $1(5.9)$ & 2.44 & $0.36,16.62$ \\
\hline HIV infection & 107 & $13(12.2)$ & 6.19 & $3.43,11.15$ \\
\hline Chronic Liver Disease & 81 & $5(6.2)$ & 2.68 & $1.10,6.54$ \\
\hline \multicolumn{5}{|l|}{ Tumor Type } \\
\hline Breast Cancer & 91 & $1(1.1)$ & Ref & \\
\hline Colorectal Cancer & 1107 & $22(2.0)$ & 1.81 & $0.25,13.26$ \\
\hline Ovarian Cancer & 345 & $9(2.6)$ & 2.37 & $0.30,18.50$ \\
\hline Small Cell Lung Cancer & 466 & $7(1.5)$ & 1.37 & $0.17,10.98$ \\
\hline NSCLC & 884 & $4(4.8)$ & 4.33 & $0.49,38.00$ \\
\hline Prostate Cancer & 71 & $0(0)$ & - & - \\
\hline Non-Hodgkin Lymphoma & 2 & $0(0)$ & - & - \\
\hline MDS & 101 & $13(12.9)$ & 11.71 & $1.56,87.78$ \\
\hline CLL & 53 & $0(0)$ & - & - \\
\hline Kaposi Sarcoma & 4 & $0(0)$ & - & - \\
\hline \multicolumn{5}{|l|}{ Chemotherapy history } \\
\hline No prior chemotherapy & 1499 & $41(2.7)$ & Ref & \\
\hline $1^{\text {st }}$ line chemotherapy & 766 & $15(2.0)$ & 0.72 & $0.40,1.29$ \\
\hline Non-1st line chemotherapy & 32 & $0(0)$ & - & - \\
\hline \multicolumn{5}{|l|}{ Hemoglobin, g/dL } \\
\hline 8 to $<10$ & 196 & $9(4.6)$ & 3.52 & $1.48,8.34$ \\
\hline $10-\leq 12(\mathrm{~F}) ; 10-\leq 14(\mathrm{M})$ & 1179 & $31(2.6)$ & 1.50 & $0.82,2.77$ \\
\hline$>12(\mathrm{~F}) ;>14(\mathrm{M})$ & 858 & $15(1.8)$ & Ref & \\
\hline \multicolumn{5}{|l|}{ Albumin, g/dL } \\
\hline$<3.0$ & 79 & $3(3.8)$ & 1.78 & $0.56,5.64$ \\
\hline$\geq 3.0$ to $<3.5$ & 208 & $7(3.4)$ & 1.58 & $0.72,3.49$ \\
\hline$\geq 3.5$ & 1830 & $39(2.1)$ & Ref & \\
\hline \multicolumn{5}{|l|}{ Lymphocytes, count $/ \mathrm{mm}^{3}$} \\
\hline$<900$ & 201 & $7(3.5)$ & 1.32 & $0.57,3.04$ \\
\hline 900 to 1499 & 515 & $15(2.9)$ & 1.10 & $0.58,2.10$ \\
\hline$\geq 1500$ & 774 & $20(2.6)$ & Ref & \\
\hline
\end{tabular}

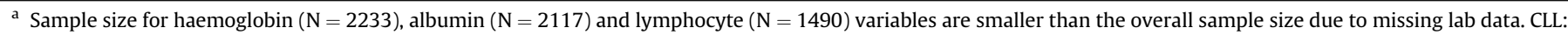
chronic lymphocytic leukemia, F: female, M: male, MDS: myelodysplastic syndrome. 
patients resulting in the prompt modification of the course of therapy before hepatotoxicity could occur, or due to the effects of cellular dedifferentiation decreasing drug metabolism (Gabbert et al., 1985; Castell et al., 2006). In line with the overall modest levels of liver chemistries that occurred, severe liver injury events were rare. Severe liver injury can be detected by concomitant transaminase and bilirubin elevations; only one patient without liver metastases exhibited this finding at baseline and one at follow-up to yield an incidence rate of 1 in 10,000 person-months. The low incidence of ALT and bilirubin elevations in our pooled database suggests that drug-induced liver injury can be sensitively detected in a clinical setting through routine monitoring, even in the presence of liver metastases.

Our study has several strengths. Our pooled database included a large number of patients across the most common types of solid tumors and hematologic malignancies, and had extensive liver chemistry data on patients with and without baseline liver metastases. Our analysis examined several measures of the prevalence, incidence, and risk factors for ALT elevations, though risk factor analyses were limited by the small number of patients with clinically relevant elevations of ALT $\geq 3 x U L N$ and further adjustments could not be performed.

To identify possible severe drug-induced liver injury, an outlier methodology based on our pooled trial cohort (Lin et al., 2012; Parks et al., 2013; Southworth and Heffernan, 2012) was used to reveal laboratory value outliers at the limits of ALT 5xULN and bilirubin 2.7xULN (Parks et al., 2013). This same methodology was also applied to fold-baseline liver chemistries (Parks et al., 2013). Among patients with and without liver metastases, the outlier limits of ALT 6.9 fold-baseline and bilirubin 6.5 fold-baseline were identified (Parks et al., 2013). Further research is needed to examine these threshold limits prospectively as liver safety signals in oncology trials and to examine the correlation of these liver chemistry thresholds with clinical outcomes. By applying these combined ALT and bilirubin liver safety signals and assessing clinical outcomes, an evidence-base can be developed to enable the safe continuation of potentially life-saving oncology therapies, rather than treatment disruption for isolated transaminase elevations, which are seldom associated with clinical sequelae. In multiple studies, isolated, transient transaminase elevations (up to 20xULN) are generally well tolerated in patients with compensated liver disease without jaundice (Chien et al., 1999; Mikl et al., 2009; Nathwani et al., 2005; Yuen et al., 2005).

Our study has limitations. The current oncology clinical studies general excluded patients with liver chemistries $\geq 5 x U L N$, therefore this dataset may not reflect the prevalence of liver enzyme elevations in the general cancer patient population. For example, marked liver chemistry elevations, mimicking acute liver failure, are reported in a small case series of rapid extensive liver infiltration with lymphoma, metastatic cancer and hematologic malignancies (Rajvanshi et al., 2005; Rowbotham et al., 1998). However, in the current study, this rarely occurred and the only two events of possible severe liver injury involved patients without baseline liver metastases.

While the current study explicitly examined baseline liver metastases, it is possible that some proportion of metastases were misdiagnosed. Among lung cancer patients, $22 \%$ of non-small cell lung cancer patients had liver metastases detected on imaging, yet up to $40 \%$ had liver metastases noted at autopsy (Quint et al., 1996). In lung, colon, and breast cancer, liver metastases are observed in $5 \%-40 \%$ of patients (Quint et al., 1996; Bengtsson et al., 1981; Hoe et al., 1991); these reports suggest that unrecognized, or microscopic, metastases likely affect many oncology patients. Baseline liver metastases were reported in $29 \%$ of patients in the current study. Fortunately, the current analysis reveals that liver metastases generally have a very limited effect on the incidence of liver chemistry elevations. Implications of our findings are that liver chemistry study stopping thresholds should be similar for patients with or without liver metastases.

In conclusion, this large, representative oncology clinical trial dataset revealed that while baseline liver chemistry elevations were more common in patients with liver metastases (versus without liver metastases), the incidence of ALT and bilirubin elevations was low and generally similar in patients with or without liver metastases during follow up, facilitating detection of outliers with potentially severe liver injury. This data supports the use of a uniform ALT and bilirubin study drug stopping threshold in patients with and without liver metastases in oncology trials, to prevent progression of potentially severe liver injury. To assess their effect on drug safety and clinical outcomes in oncology clinical trials, liver chemistry thresholds identified by truncated robust multivariate outlier detection methodology (Parks et al., 2013) can now be examined prospectively as drug stopping thresholds in studies.

\section{Conclusions}

Our study provides an evidence-based assessment of the rates of possible liver injury due to clinically relevant patient factors and potential drug-induced injury. Our findings may serve to standardize thresholds for study drug cessation, facilitate earlier identification of possible drug-induced liver injury, inform inclusion/ exclusion criteria for cancer trials, and help to elucidate the etiology of abnormal liver chemistries in oncology patients. These liver chemistry analyses provide valuable comparative liver safety results for future oncology studies. Our study may serve to develop evidence-based liver chemistry subject stopping thresholds for oncology clinical trials which may enable therapy continuation.

\section{Conflict of interest}

SS, AL and SL are employees of GlaxoSmithKline (GSK); SS and SL own GSK shares. CMH was a GSK employee during the conduct of this study and is now a consultant for Furiex and Otsuka Pharmaceuticals. GSK funded this study.

\section{Acknowledgments}

We would like to thank Nittaya Suppapanya for her analytical support on this study. GSK funded this study.

\section{Appendix A. Supplementary data}

Supplementary data related to this article can be found at http:// dx.doi.org/10.1016/j.yrtph.2016.03.019.

\section{Transparency document}

Transparency document related to this article can be found online at http://dx.doi.org/10.1016/j.yrtph.2016.03.019.

\section{References}

Armitage, P., Berry, G., Matthews, J.N.S., 2002. Statistical Methods in Medical Research. Blackwell Science Ltd., Oxford.

Bengtsson, G., Carlsson, G., Hafstrom, L., Jonsson, P.E., 1981. Natural history of patients with untreated liver metastases from colorectal cancer. Am. J. Surg. 141, $586-589$.

Castell, J.V., Jover, R., Martinez-Jimenez, C.P., Gomez-Lechon, M.J., 2006. Hepatocyte cell lines: their use, scope and limitations in drug metabolism studies. Expert Opin. Drug Metab. Toxicol. 2, 183-212.

Chien, R.N., Liaw, Y.F., Atkins, M., 1999. Pretherapy alanine transaminase level as a determinant for hepatitis B e antigen seroconversion during lamivudine 
therapy in patients with chronic hepatitis B. Asian Hepatitis Lamivudine Trial Group. Hepatology 30, 770-774.

Gabbert, H., Wagner, R., Moll, R., Gerharz, C.D., 1985. Tumor dedifferentiation: an important step in tumor invasion. Clin. Exp. Metastasis 3, 257-279.

Green, R.M., Flamm, S., 2002. AGA technical review on the evaluation of liver chemistry tests. Gastroenterology 123, 1367-1384.

Hoe, A.L., Royle, G.T., Taylor, I., 1991. Breast liver metastases-incidence, diagnosis and outcome. J. R. Soc. Med. 84, 714-716.

Kaplowitz, N., 2005. Idiosyncratic drug hepatotoxicity. Nat. Rev. Drug Discov. 4. 489-499.

Lee, W.M., 2003. Drug-induced hepatotoxicity. N. Engl. J. Med. 349, 474-485.

Lin, X., Parks, D., Painter, J., Hunt, C.M., Stirnadel-Farrant, H.A., et al., 2012. Validation of multivariate outlier detection analyses used to identify potential druginduced liver injury in clinical trial populations. Drug Saf. 35, 865-875.

Mikl, J., Sulkowski, M.S., Benhamou, Y., Dieterich, D., Pol, S., et al., 2009. Hepatic profile analyses of tipranavir in phase II and III clinical trials. BMC Infect. Dis. 9, 203.

Nathwani, R.A., Kumar, S.R., Reynolds, T.B., Kaplowitz, N., 2005. Marked elevation in serum transaminases: an atypical presentation of choledocholithiasis. Am. J. Gastroenterol. 100, 295-298.

Parks, D., Lin, X., Painter, J.L., Cheng, J., Hunt, C.M., et al., 2013. A proposed modification to Hy's law and Edish criteria in oncology clinical trials using aggregated historical data. Pharmacoepidemiol Drug Saf. 22, 571-578.

Quint, L.E., Tummala, S., Brisson, L.J., Francis, I.R., Krupnick, A.S., et al., 1996. Distribution of distant metastases from newly diagnosed non-small cell lung cancer. Ann. Thorac. Surg. 62, 246-250.

Rajvanshi, P., Kowdley, K.V., Hirota, W.K., Meyers, J.B., Keeffe, E.B., 2005. Fulminant hepatic failure secondary to neoplastic infiltration of the liver. J. Clin. Gastroenterol. 39, 339-343.

Rowbotham, D., Wendon, J., Williams, R., 1998. Acute liver failure secondary to hepatic infiltration: a single centre experience of 18 cases. Gut 42, 576-580.

Southworth, H., Heffernan, J.E., 2012. Extreme value modelling of laboratory safety data from clinical studies. Pharm. Stat. 11, 361-366.

US FDA, July 2009. Guidance for Industry. Drug-induced Liver Injury: Premarketing Clinical Evaluation. United States Food and Drug Administration. Available at. http://www.fda.gov/downloads/Drugs/.../Guidances/UCM174090.pdf (accessed: 22.02.15.).

Weil, J.G., Bains, C. Linke, A., Clark, D.W., Stirnadel, H.A., et al., 2008. Background incidence of liver chemistry abnormalities in a clinical trial population without underlying liver disease. Regul. Toxicol. Pharmacol. 52, 85-88.

Yuen, M.F., Yuan, H.J., Wong, D.K., Yuen, J.C., Wong, W.M., et al., 2005. Prognostic determinants for chronic hepatitis B in Asians: therapeutic implications. Gut 54 1610-1614. 